Article

\title{
Prototyping of LAI and FPAR Retrievals from MODIS Multi-Angle Implementation of Atmospheric Correction (MAIAC) Data
}

\author{
Chi Chen ${ }^{1, *}$, Yuri Knyazikhin ${ }^{1}$, Taejin Park ${ }^{1}$, Kai Yan ${ }^{1,3}{ }^{\text {, Alexei Lyapustin }}{ }^{2}$, Yujie Wang ${ }^{2}$, \\ Bin Yang ${ }^{1,4}$ and Ranga B. Myneni ${ }^{1}$ \\ 1 Department of Earth and Environment, Boston University, 685 Commonwealth Avenue, \\ Boston, MA 02215, USA; jknjazi@bu.edu (Y.K.); taejin1392@gmail.com (T.P.); \\ kaiyan.earthscience@gmail.com (K.Y.); ybjason@bu.edu (B.Y.); ranga.myneni@gmail.com (R.B.M.) \\ 2 Goddard Space Flight Center, National Aeronautics and Space Administration, Greenbelt, MD 20771, USA; \\ alexei.i.lyapustin@nasa.gov (A.L.); yujie.wang-1@nasa.gov (Y.W.) \\ 3 State Key Laboratory of Remote Sensing Science, Institute of Remote Sensing Science and Engineering, \\ Faculty of Geographical Science, Beijing Normal University, Beijing 100875, China \\ 4 Beijing Key Lab of Spatial Information Integration \& Its Applications, Institute of RS \& GIS, \\ Peking University, Beijing 100871, China \\ * Correspondence: chenchi@bu.edu; Tel.: +86-1-617-353-8846
}

Academic Editors: Alfredo R. Huete, Clement Atzberger and Prasad S. Thenkabail Received: 25 December 2016; Accepted: 13 April 2017; Published: 15 April 2017

\begin{abstract}
Leaf area index (LAI) and fraction of photosynthetically active radiation (FPAR) absorbed by vegetation are key variables in many global models of climate, hydrology, biogeochemistry, and ecology. These parameters are being operationally produced from Terra and Aqua MODIS bidirectional reflectance factor (BRF) data. The MODIS science team has developed, and plans to release, a new version of the BRF product using the multi-angle implementation of atmospheric correction (MAIAC) algorithm from Terra and Aqua MODIS observations. This paper presents analyses of LAI and FPAR retrievals generated with the MODIS LAI/FPAR operational algorithm using Terra MAIAC BRF data. Direct application of the operational algorithm to MAIAC BRF resulted in an underestimation of the MODIS Collection 6 (C6) LAI standard product by up to $10 \%$. The difference was attributed to the disagreement between MAIAC and MODIS BRFs over the vegetation by $-2 \%$ to $+8 \%$ in the red spectral band, suggesting different accuracies in the BRF products. The operational LAI/FPAR algorithm was adjusted for uncertainties in the MAIAC BRF data. Its performance evaluated on a limited set of MAIAC BRF data from North and South America suggests an increase in spatial coverage of the best quality, high-precision LAI retrievals of up to $10 \%$. Overall MAIAC LAI and FPAR are consistent with the standard C6 MODIS LAI/FPAR. The increase in spatial coverage of the best quality LAI retrievals resulted in a better agreement of MAIAC LAI with field data compared to the C6 LAI product, with the RMSE decreasing from 0.80 LAI units (C6) down to 0.67 (MAIAC) and the $\mathrm{R}^{2}$ increasing from 0.69 to 0.80 . The slope (intercept) of the satellite-derived vs. field-measured LAI regression line has changed from $0.89(0.39)$ to $0.97(0.25)$.
\end{abstract}

Keywords: MAIAC; MODIS; leaf area index (LAI); fraction of photosynthetically active radiation (FPAR); radiative transfer

\section{Introduction}

The MODerate Resolution Imaging Spectroradiometer (MODIS) is a key instrument onboard NASA's Earth Observing System (EOS) Terra and Aqua satellites, which were launched in December 1999 and May 2002, respectively [1]. The MODIS standard products include leaf area index (LAI) and 
the fraction of photosynthetically active radiation (FPAR, $400 \mathrm{~nm}-700 \mathrm{~nm}$ ) absorbed by vegetation [2-7], which are being operationally produced from the Terra and Aqua bidirectional reflectance factor (BRF). LAI and FPAR are key parameters in modeling the circulation of energy, water, and carbon between the land, atmosphere, and ecosystems [8].

The MODIS science team has developed, and plans to release, a new version of the BRF product, called multi-angle implementation of atmospheric correction (MAIAC), from Terra and Aqua MODIS observations [9-11]. Both the standard and MAIAC BRFs are derived from data acquired by the same instrument $[11,12]$. However, different techniques were implemented to correct in-orbit data for atmosphere effects. Ideally, LAI and FPAR datasets derived from the MAIAC data using the MODIS LAI/FPAR operational algorithm should compare well with the standard MODIS LAI product. The retrievals, however, can disagree because uncertainties in the BRF products are different. The algorithm must be calibrated using information on uncertainties in inputs before its use in operational data processing. The aim of this paper is to calibrate the MODIS LAI/FPAR operational algorithm for use with MAIAC data, generate LAI and FPAR datasets, and analyze the retrievals for spatial coverage, accuracy, and consistency with the standard MODIS LAI and FPAR products.

The paper is organized as follows: A description of the MODIS LAI/FPAR algorithm, its inputs, and validation sites are presented in Section 2. Analyses of standard and MAIAC BRFs, LAI fields retrieved from the BRFs, and algorithm calibration are discussed in Section 3. The calibrated algorithm was applied to generate LAI and FPAR from the MAIAC BRF over selected regions. The retrievals are analyzed in Section 4. Finally, Section 5 summarizes the results.

\section{Materials}

\subsection{MODIS LAI/FPAR Algorithm}

The operational MODIS LAI/FPAR algorithm ingests BRF in the red and near-infrared (NIR) spectral bands, their uncertainties, sun-sensor geometry, and biome classification map and retrieves the LAI/FPAR for each MODIS pixel [2,3,13-15]. The retrieval technique includes the main algorithm, which is based on the 3D radiative transfer equation, and the backup algorithm, which uses empirical relationships between normalized difference vegetation index (NDVI) and LAI, and FPAR. The main algorithm compares the observed spectral BRF with those evaluated from the model-based entries stored in a look-up-table (LUT) for a suite of canopy structures and soil patterns that represent an expected range of typical conditions for a given biome type. All canopy/soil patterns for which modeled and observed BRFs differ within a specified uncertainty level are considered as acceptable solutions. The mean values of LAI and FPAR and their dispersions are reported as retrievals and their uncertainties. When this method fails to localize a solution, the backup method is utilized.

Analyses of the MODIS LAI/FPAR algorithm performance indicate that best quality, high-precision retrievals are obtained from the main algorithm $[2,3,16,17]$. In the case of dense canopies, the reflectances saturate and, therefore, are weakly sensitive to changes in canopy properties. The reliability of parameters retrieved under the condition of saturation is lower than that generated by the main algorithm using unsaturated BRF [15]. Such retrievals are flagged. The algorithm path, therefore, is the key quality assessment (QA) flag that provides information about the overall quality of the LAI/FPAR. It includes four values (from highest to lowest quality): the main algorithm without saturation, the main algorithm with saturation, the backup algorithm due to sun-sensor geometry, and the backup algorithm due to other reasons. The QA variables also provide information about the cloud state, aerosol load, and the presence of snow, which are inherited from the upstream BRF product.

The daily retrievals are composited over an 8-day period by selecting the LAI and FPAR pair corresponding to the maximum FPAR value generated by the main algorithm. The backup algorithm retrievals are selected only when no main algorithm retrievals are available during the 8-day compositing period. The 8-day composited LAI/FPAR product is distributed to the public from the NASA EOSDIS Land Processes Distributed Active Archive Center (LP DAAC) [4,5]. 


\subsection{MODIS Biome Classification Map}

A biome classification map is an important input for the LAI/FPAR retrieval algorithm. It reduces the number of unknowns of the inverse problem through the use of simplifying assumptions (e.g., leaf normal orientation) and standard constants (e.g., leaf albedo, patterns of ground reflectance) that are assumed to vary with the biome [13-15]. The biome map utilized in the Collection 6 (C6) MODIS LAI/FPAR algorithm is used in our study [2,3]. It stratifies the global vegetation into eight architectural types, or biomes: grasses/cereal crops (Biome 1), shrubs (Biome 2), broadleaf crops (Biome 3), savannas (Biome 4), evergreen broadleaf forests (Biome 5), deciduous broadleaf forests (Biome 6), evergreen needleleaf forests (Biome 7), and deciduous needleleaf forests (Biome 8).

\subsection{MAIAC and MOD09GA BRF}

Daily Terra MAIAC BRF [11] and standard C6 MODIS BRF, called MOD09GA [18], products used in this study are at 500-m sinusoidal grids. The globe is tiled into 36 horizontal tiles along the east-west, and 18 vertical tiles along the north-south axes [19]. Each tile is identified by its horizontal (h) and vertical (v) coordinates, e.g., h10v05. Both products provide sun-sensor geometry. In addition, QA variables accompanying the products provide information about the overall retrieval quality and observation conditions. The MAIAC retrieval approach combines a new set of algorithms, which utilizes the radiative transfer theory and spatiotemporal imagery processing techniques to retrieve aerosols and correct observations for atmosphere effects. This technique improves the accuracy and stability of the surface spectral BRF over regions with thick clouds, snow, and water, e.g., over tropical regions [9-11]. In the tropics, for example, the MAIAC algorithm generates a more accurate, less conservative cloud mask, which increases the number of clear-sky scenes by a factor of about 2-5, compared to MOD09GA [20-22].

Our analysis is focused on seven tiles from North and South America acquired during the year 2002 that represent eight biome types recognized by the operational algorithm and contain validation sites for which field data on LAI and FPAR are available. The tiles are h10v05, h11v04, h11v10, h12v03, h12v04, h12v09, and h13v11.

\subsection{MODIS C6 LAI/FPAR Product}

The Terra MODIS C6 8-day composited LAI/FPAR (MOD15A2H) from the seven selected tiles (Section 2.3) are used as a reference dataset. C6 LAI/FPAR product at 500-m spatial resolution and 8-day temporal frequency was generated from C6 MOD09GA surface reflectance. It represents the latest version and contains the entire time series from February 2000 to the present $[2,13-15]$. The C6 LAI/FPAR product is comprehensively evaluated and validated, which gives high confidence on its accuracy and consistency with other existing LAI/FPAR products [2,3]. The standard product is composed from an intermediate daily LAI/FPAR product by selecting the best values from retrievals generated during the 8 -day compositing periods [2,23]. The daily retrievals in the seven selected tiles are also used in our study.

\subsection{Validation Sites}

Field data of LAI is publicly available from the Calibration Validation Portal (CalValPortal) On-Line Interactive Validation Exercise (OLIVE) are used in this study [24]. This website provides a collection of sites (called DIRECT) for which ground measurements have been collected and processed according to the Committee of Earth Observing Satellites (CEOS) Land Product Validation (LPV) subgroup guidelines $[25,26]$. These site-specific LAIs are available as spatially-averaged values over $3 \mathrm{~km} \times 3 \mathrm{~km}$ reference maps. A summary of the sites used in this study is given in Table S1. 


\section{Methods}

The goal of this section is to calibrate the operational MODIS LAI/FPAR algorithm for use with MAIAC data. We begin with analyses of the difference between MOD09GA and MAIAC BRFs. To understand the impact of uncertainties on retrievals we apply the operational algorithm to the MAIAC BRF without any adjustments and compare the retrievals with the C6 LAI product. Finally, we calibrate the algorithm using information on uncertainties in the MAIAC data.

\subsection{Analysis of MAIAC BRF and MOD09GA}

We analyzed the MAIAC and MOD09GA daily BRFs in the red and NIR spectral bands over the selected tiles (Section 2.3) acquired during the compositing period between 4 and 11 July 2002 (day of year (DOY) between 185 and 192). We grouped the BRFs into pixels with "good quality" if both MAIAC and MOD09GA QA flags met the criteria shown in Table 1. The "good quality" data excludes contamination by cloud, high aerosol content, presence of cirrus, snow, and fire. Its percentage for different biome types varied between $18.76 \%$ and $43.67 \%$ (Table 2). The remaining pixel BRFs in the selected regions were retrieved under poorer observation conditions according to the QA flags. These pixels were flagged as pixels with "poor quality" BRFs. They comprised 3.05\% to $10.32 \%$ of the total number of biome-dependent observations (Table 2) and consisted mainly of pixels for which the MAIAC QA flag passed the "good quality" test, whereas MOD09GA QA indicated cloud contamination and/or high aerosol content. This is consistent with results reported in $[20,22]$. The reminder mainly includes pixels for which the MAIAC atmospheric correction algorithm returned a fill value (Table 2), i.e., the BRF cannot be retrieved according to the algorithm logic. The MOD09GA operational algorithm, however, generates a BRF value and associated QA flags in this case. Therefore, the users should consult QA flags when using MOD09GA data. Our analyses were performed separately for subsets of good- and poor-quality pixels.

On average, the MAIAC BRF retrieval algorithm produced higher reflectance values in the red spectral band for the subset of good-quality pixels compared to its MOD09GA counterpart. The difference varies between $-2 \%$ (Biome 5 ) and $+8 \%$ (Biome 3 ) in this example (Table 3 ). Some previous studies reported that MOD09 red BRF is slightly underestimated with respect to in situ measurements $[27,28]$. The BRFs differ insignificantly in the NIR spectral band, with the relative difference between $-0.6 \%$ and $1.3 \%$ (Table S2). Both products exhibit similar spatial variations within biome types in the red and NIR spectral bands. The MOD09GA red BRF is significantly higher than the MAIAC reflectance for pixels with poor quality data, with the difference varying between $-48 \%$ (Biome 2) and $-0.4 \%$ (Biome 4 ) (Table 3). An increase in the difference is also seen in the NIR spectral band (Table S2).

The observed increase in the product difference for pixels with poor quality data is due to the significant increase in the MOD09GA BRF. Indeed, the mean BRF in the red spectral band retrieved by the MOD09GA algorithm under poor observation conditions biased expected values by $-96 \%$ (Biome 2) to $-15 \%$ (Biome 3 and 5). The MOD09GA BRF in the NIR spectral band exhibits a similar tendency, although the magnitude of changes is reduced.

The MAIAC retrieval algorithm is less sensitive to the observation conditions: the difference between mean BRFs retrieved under good and poor observation conditions varies between $-18 \%$ (Biome 4 ) and $+9 \%$ (Biome 3 ) in the red, and between $-12 \%$ (Biome 4 ) and $+2 \%$ (Biomes 7 ) in the NIR spectral band. This is a consequence of the MAIAC atmosphere correction approach [11]. Indeed, the algorithm performs an analysis of 4- to 16-day time series of at-sensor radiance collected over fixed-sized areas (blocks). Assuming that the surface remains stable or changes slowly over the measurement period of 4 to 16 days, the variation in radiance registered by the sensor is due to variation in atmospheric conditions. Analyses of temporal and spatial variations improve the accuracy of cloud detection, aerosol retrievals and, consequently, atmospheric correction with minimal conceptual limitations. In the case of rapid or large magnitude changes, the MAIAC assumes a stable BRDF shape, but a variable magnitude of total reflectance. The MAIAC algorithm is more expensive 
than its MOD09GA counterpart in terms of the computer resources required to process the time series and retrieve the surface BRF for a given block.

The MOD09GA retrieval approach uses a pixel-by-pixel technique, i.e., the algorithm derives the surface reflectance in Lambertian approximation from a single record of the spectral at-sensor radiance. Unlike the MAIAC approach that aims to extract information about the surface and atmosphere directly from the time series and spatial analyses of the sensor records, the MOD09GA algorithm uses a number of assumptions to compensate for the poor information content of a single observation. This increases the algorithm uncertainty. The MOD09GA is faster than the MAIAC algorithm. However, it is capable of generating reliable BRFs only if the algorithm assumptions are met. This lowers the spatial coverage of good quality BRFs.

Table 1. Quality Assessment (QA) variables for MAIAC BRF and MOD09GA products.

\begin{tabular}{cccccccc}
\hline Product & Cloud/Shadow & Aerosol & Cirrus & Snow/Ice & $\begin{array}{c}\text { Adjacent } \\
\text { Cloud Mask }\end{array}$ & Fire & $\begin{array}{c}\text { Algorithm } \\
\text { Initialized Status }\end{array}$ \\
\hline MAIAC & No & Low & - & No & No & No & Yes \\
MOD09GA & No & Low & No & No & No & No & - \\
\hline
\end{tabular}

Table 2. Statistics of good and poor quality input for DOY 185-192, 2002.

\begin{tabular}{ccccccccc}
\hline & Biome 1 & Biome 2 & Biome 3 & Biome 4 & Biome 5 & Biome 6 & Biome 7 & Biome 8 \\
\hline Total area, $\mathrm{km}^{2}$ & 601,924 & 265,006 & 381,059 & 501,265 & $1,295,335$ & 509,444 & 581,865 & 38,883 \\
$\begin{array}{c}\text { Good quality, \% } \\
\text { Poor quality, \% }\end{array}$ & 24.07 & 33.96 & 18.76 & 19.69 & 43.67 & 23.23 & 40.62 & 38.61 \\
$\begin{array}{c}\text { Fill value in MAIAC } \\
\text { and MOD09GA, \% }\end{array}$ & 2.25 & 9.42 & 10.32 & 3.05 & 3.80 & 8.85 & 7.93 & 8.42 \\
$\begin{array}{c}\text { Fill value in MAIAC } \\
\text { and valid BRF }\end{array}$ & 67.39 & 1.70 & 4.46 & 15.77 & 0.45 & 0.22 & 0.09 \\
MOD09GA, \% & & 56.61 & 69.22 & 72.80 & 36.77 & 67.47 & 51.24 & 52.89 \\
\hline
\end{tabular}

Table 3. Comparison of MOD09GA and MAIAC daily red BRF during DOY 185-192, 2002.

\begin{tabular}{|c|c|c|c|c|c|c|c|c|c|}
\hline & & B1 & B2 & B3 & B4 & B5 & B6 & B7 & B8 \\
\hline \multirow{5}{*}{ Good quality } & $\overline{\mathrm{BRF}_{\mathrm{MOD} 09}}$ & 0.059 & 0.048 & 0.063 & 0.072 & 0.024 & 0.027 & 0.033 & 0.040 \\
\hline & Coefficient of variation, $\%$ & 42.37 & 22.92 & 38.10 & 30.56 & 29.17 & 33.33 & 30.30 & 25.00 \\
\hline & $\overline{\mathrm{BRF}}$ MAIAC & 0.062 & 0.050 & 0.068 & 0.073 & 0.023 & 0.029 & 0.034 & 0.041 \\
\hline & Coefficient of variation, $\%$ & 40.32 & 22.00 & 35.29 & 28.77 & 30.43 & 31.03 & 32.35 & 24.39 \\
\hline & Difference ${ }^{1}, \%$ & 4.98 & 2.60 & 7.82 & 1.06 & -2.05 & 6.67 & 2.63 & 3.54 \\
\hline \multirow{5}{*}{ Poor quality } & $\overline{\mathrm{BRF}_{\mathrm{MOD} 09}}$ & 0.088 & 0.092 & 0.065 & 0.080 & 0.028 & 0.034 & 0.054 & 0.068 \\
\hline & Coefficient of variation, $\%$ & 110.23 & 153.26 & 78.46 & 40.00 & 50.00 & 132.35 & 155.56 & 150.00 \\
\hline & $\overline{\overline{B R F}}$ MAIAC & 0.063 & 0.048 & 0.058 & 0.079 & 0.026 & 0.028 & 0.033 & 0.040 \\
\hline & Coefficient of variation, $\%$ & 38.10 & 31.25 & 39.66 & 39.24 & 46.15 & 39.29 & 39.39 & 35.00 \\
\hline & Difference, \% & -28.43 & -47.51 & -10.24 & -0.41 & -4.78 & -17.63 & -37.93 & -41.06 \\
\hline \multirow{2}{*}{ MOD09GA } & Good-Poor $^{2}, \times 10^{-2}$ & -3.45 & -4.36 & -0.62 & -1.24 & -0.31 & -0.65 & -2.01 & -2.93 \\
\hline & (Good-Poor)/Good, \% & -70.18 & -96.45 & -15.01 & -20.38 & -15.01 & -28.38 & -64.11 & -81.65 \\
\hline \multirow{2}{*}{ MAIAC } & Good-Poor, $\times 10^{-2}$ & -0.29 & 0.00 & 0.69 & -1.16 & -0.14 & 0.12 & 0.13 & 0.00 \\
\hline & (Good-Poor)/Good, \% & -10.49 & -1.39 & 8.72 & -18.19 & -9.53 & 0.54 & 1.68 & -1.53 \\
\hline
\end{tabular}

${ }^{1}$ Difference is defined as $\overline{\left(\mathrm{BRF}_{\text {MAIAC }}-\mathrm{BRF}_{\text {MOD09 }}\right) / \mathrm{BRF}_{M O D 09}} \times 100 \% .{ }^{2}$ Good-Poor is defined as the average of pixel-wise difference between Good and Poor condition observations during the 8-day period.

\subsection{Direct Application of the Operational Algorithm to MAIAC BRF Data}

We generated 8-day LAI products for the compositing period between 4 and 11 July 2002 over the selected regions (Section 2.3) with the MODIS LAI/FPAR operational algorithm using MAIAC BRF as the input. Here we focus on the MAIAC and C6 LAI over pixels with "good quality" input.

Table 4 (rows 1-3) shows the mean, coefficient of variation (std/mean) of the MAIAC and C6 LAI products, and their mean difference relative to the C6 LAI for good quality data as a function of biome 
type. Overall the retrievals show systematic disagreement for all vegetation types. The difference in mean values are within 0.2 LAI units. The coefficients of variation of the MAIAC and C6 LAI products are in close agreement, indicating that both retrievals exhibit similar spatial variability within each biome type.

However, the MAIAC LAI tends to underestimate its C 6 counterpart by about $3 \%$ to $10 \%$ (Table 4 ). Recall that the good quality BRF generated by the MAIAC and MOD09GA algorithms agree well in the NIR and disagree by $-2 \%$ to $+8 \%$ in the red spectral band (Table 3 ). The higher red BRF, with an almost indistinguishable difference in the NIR BRF, caused the underestimation of the LAI product. The quality of retrievals can be influenced by the use of uncertainty information in the retrieval technique [29]. Model and observation uncertainties are inputs to the LAI operational algorithm. We use this feature to calibrate the operational LAI algorithm for MAIAC-specific uncertainties.

Table 4. Difference between MAIAC and MODIS C6 LAI over pixels with good quality input for the compositing period between 4 and 11 July 2002, before and after algorithm calibration.

\begin{tabular}{|c|c|c|c|c|c|c|c|c|c|}
\hline \multicolumn{2}{|c|}{ Biome Type } & \multirow{3}{*}{$\begin{array}{c}\text { B1 } \\
2.31 \\
46.98\end{array}$} & \multirow{3}{*}{$\begin{array}{c}\text { B2 } \\
1.38 \\
33.82\end{array}$} & \multirow{3}{*}{$\begin{array}{c}\text { B3 } \\
1.66 \\
30.46\end{array}$} & \multirow{3}{*}{$\begin{array}{c}\text { B4 } \\
1.13 \\
31.67\end{array}$} & \multirow{3}{*}{$\begin{array}{c}\text { B5 } \\
5.89 \\
8.67\end{array}$} & \multirow{3}{*}{$\begin{array}{c}\text { B6 } \\
5.19 \\
15.60\end{array}$} & \multirow{3}{*}{$\begin{array}{c}\text { B7 } \\
2.67 \\
31.45\end{array}$} & \multirow{3}{*}{$\begin{array}{c}\text { B8 } \\
2.46 \\
30.95\end{array}$} \\
\hline & Mean LAI & & & & & & & & \\
\hline C6 LAI & Coefficient of variation, $\%$ & & & & & & & & \\
\hline (Before algorithm calibration) & Coefficient of variation, $\%$ & 44.19 & 34.62 & 27.93 & 29.75 & 7.79 & 15.55 & 31.60 & 30.27 \\
\hline \multirow{2}{*}{$\begin{array}{c}\text { Difference } \\
\text { (Before algorithm calibration) }\end{array}$} & Absolute & -0.20 & -0.06 & -0.17 & -0.04 & +0.01 & -0.05 & -0.10 & -0.12 \\
\hline & Relative $^{1}, \%$ & -8.59 & -4.33 & -9.95 & -3.19 & +0.20 & -0.97 & -3.86 & -4.77 \\
\hline \multirow{2}{*}{$\begin{array}{c}\text { MAIAC LAI } \\
\text { (After algorithm calibration) }\end{array}$} & Mean LAI & 2.30 & 1.37 & 1.68 & 1.13 & 5.85 & 5.18 & 2.68 & 2.50 \\
\hline & Coefficient of variation, $\%$ & 45.79 & 34.80 & 30.41 & 30.38 & 7.72 & 14.37 & 32.20 & 31.17 \\
\hline \multirow{3}{*}{$\begin{array}{c}\text { Difference } \\
\text { (After algorithm calibration) }\end{array}$} & Absolute & -0.01 & -0.01 & 0.01 & 0.00 & -0.04 & -0.01 & 0.01 & 0.05 \\
\hline & Relative, \% & -0.48 & -0.67 & 0.83 & -0.10 & -0.63 & -0.22 & 0.44 & 1.88 \\
\hline & Precision & 0.53 & 0.11 & 0.19 & 0.15 & 0.29 & 0.66 & 0.43 & 0.41 \\
\hline
\end{tabular}

${ }^{1}$ Relative difference is calculated as spatially averaged pixel values of (MAIAC LAI - C6 LAI)/C6 LAI $\times 100 \%$ over each biome.

\subsection{Calibration of the Operational LAI/FPAR Algorithm}

\subsubsection{Observation, Model, and Stabilized Precisions}

Let $r_{1}, r_{2}, \ldots, r_{n}$ be the atmospherically corrected surface BRFs at $n$ spectral bands. The surface reflectances are obtained by correcting the at-sensor radiance for atmospheric effects. The correction technique introduces errors in the surface reflectance product. The operational LAI/FPAR algorithm treats spectral BRFs as independent random variables with finite variances $\sigma_{k}^{2}, k=1,2, \ldots, n$, and assumes that the deviations $\varepsilon_{k}=\left(r_{k}-m_{k}\right) / \sigma_{k}$ follow a Gaussian distribution [29]. Here, $m_{k}$ is the mathematical expectation of $r_{k}$, which approximates a true value. The random variable:

$$
\chi_{\sigma}^{2}[\mathbf{r}-\mathbf{m}]=\sum_{k=1}^{n} \varepsilon_{k}^{2}=\sum_{k=1}^{n} \frac{\left(r_{k}-m_{k}\right)^{2}}{\sigma_{k}^{2}}
$$

characterizing the proximity of atmospherically corrected data $\mathbf{r}=\left(r_{1}, r_{2}, \ldots, r_{n}\right)$ to the expected values, $\mathbf{m}=\left(m_{1}, m_{2}, \ldots, m_{n}\right)$ has a chi-square distribution. The inequality $\chi_{\sigma}^{2} \leq n$ indicates good accuracy. We assume that the atmospheric correction algorithm provides spectral reflectance r satisfying $\chi_{\sigma}^{2} \leq n$ with a probability $1-\alpha$. Dispersions $\sigma=\left(\sigma_{1}, \sigma_{2}, \ldots, \sigma_{n}\right)$ are observation precisions, i.e., precision in the BRF product. The deviation of $\mathbf{m}$ from a true vector is the measurement accuracy, or bias. The uncertainty is defined as the root mean squared error (RMSE) between the estimated and true values, which depends on both accuracy and precision [30].

The MODIS LAI operational algorithm compares measured spectral BRF, $\mathbf{r}$, with those evaluated from model-based entries, $\mathbf{r}_{M}=\left(r_{M, 1}, r_{M, 2}, \ldots, r_{M, n}\right)$, stored in the LUT. The model-based spectral BRF also has errors, which are characterized by values $\varepsilon_{M, k}=\left(r_{M, k}-m_{M, k}\right) / \sigma_{M, k}$. Dispersions $\sigma_{M}=\left(\sigma_{M, 1}, \sigma_{M, 2}, \ldots, \sigma_{M, n}\right)$ are model precisions, which are determined by the range of natural 
variation in biophysical parameters not accounted for by the model. Deviations of the model predictions, $m_{M, k}$, from true values characterize the model accuracy.

Both the observation and model precisions must be taken into account when comparing measured and modeled BRFs [29]. Ignoring the model precision in the retrieval algorithm can cause a destabilization of the retrieval process. Wang et al. [29] introduced a stabilized precision, $\delta=\left(\delta_{1}, \delta_{2}, \ldots, \delta_{n}\right)$, which prevents the destabilization and minimizes the impact of model and observation precisions on LAI retrievals. The stabilized precision is a function of $\sigma_{M}$ and $\sigma$.

The main LAI algorithm uses the stabilized precision to select acceptable solutions, i.e., all canopy/soil parameters for which modeled, $\mathbf{r}_{M}$, and measured, $\mathbf{r}$, spectral BRFs agree within the stabilized precisions, i.e., $\chi_{\delta}^{2}\left[\mathbf{r}-\mathbf{r}_{M}\right] \leq n$. The mean values of LAI/FPAR and their dispersions are reported as retrievals and their uncertainties.

\subsubsection{Calibration Approach}

The MODIS LAI operational algorithm uses BRFs at two $(n=2)$ spectral bands, red (band $k=1$ ) and NIR $(k=2)$, to retrieve the LAI. The MAIAC observation precision is expected to be high when the surface is stable or changes slowly over the measurement period. In the case of rapid or large magnitude changes, the MAIAC assumes a stable BRDF shape, but a variable magnitude of total reflectance and, thus, its precision can be comparable to that of MOD09GA [11]. To take the worst case (rapid or large magnitude change) into account, the stabilized precision is, therefore, set to that used to generate the C6 MODIS LAI product [29,31,32]. Its relative values, $\delta_{k} / r_{k}$, are given in Table 5 .

Our analyses (Section 3.1) have indicated that the expected values $m_{1}$ of red BRF over the subset of good-quality surface reflectance derived from MAIAC and MOD09GA data are different, indicating different product accuracies. Let $\mathbf{m}_{T}=\left(m_{T, 1}, m_{T, 2}\right)$ and $\mathbf{m}_{M}=\left(m_{M, 1}, m_{M, 2}\right)$ represent the true values of the spectral BRF and the expected values predicted by the model. It follows from the Minkowski inequality $[29,33]$ that:

$$
\chi_{\delta}\left[\mathbf{r}-\mathbf{r}_{M}\right] \leq \chi_{\delta}[\mathbf{r}-\mathbf{m}]+\chi_{\delta}\left[\mathbf{r}_{M}-\mathbf{m}_{M}\right]+\chi_{\delta}\left[\mathbf{m}-\mathbf{m}_{M}\right]
$$

This equation shows that $\chi_{\delta}$ depends on how the modeled BRF differs from (a) the "true" canopy BRF and (b) the observed BRF. For example, the use of a very accurate model, i.e., $\mathbf{m}_{M}=\mathbf{m}_{T}$, maximizes the term $\chi_{\delta}\left[\mathbf{m}-\mathbf{m}_{M}\right]$. This may cause a "true" LAI to be outside of the set of acceptable solutions, i.e., it does not pass the comparison test. This term vanishes if one uses a model that tends to simulate the measurements, i.e., $\mathbf{m}_{M}=\mathbf{m}$. This, however, increases the contribution of the term $\chi_{\delta}\left[\mathbf{r}_{M}-\mathbf{m}_{M}\right]$. The calibration, therefore, is reduced to finding a surface reflectance model that optimally approximates the observed, $\mathbf{m}$, and the true surface spectral BRF, $\mathbf{m}_{T}$.

The MODIS operational LAI algorithm is based on the radiative transfer of canopy spectral invariants, which permits an accurate decoupling of the structural and radiometric components of modeled and/or measured spectral BRF [14,34-37]. The structural component determines the BRF shape, whereas the single scattering albedo controls its magnitude and accounts for the variation in BRF with the sensor spatial resolution and spectral band composition [38]. The MAIAC and MOD09GA BRFs are derived from data acquired by the same instrument, i.e., the sensor spectral band composition and the resolution are the same. The single scattering albedo that appears in the surface BRF model is the adjustable parameter that controls Equation (2) and, consequently, the performance of the LAI/FPAR retrieval technique.

Table 5. Relative values of stabilized precision in BRF used to generate MODIS C6 LAI product.

\begin{tabular}{ccccccccc}
\hline & Biome 1 & Biome 2 & Biome 3 & Biome 4 & Biome 5 & Biome 6 & Biome 7 & Biome 8 \\
\hline Red & 0.2 & 0.2 & 0.2 & 0.2 & 0.3 & 0.3 & 0.3 & 0.3 \\
NIR & 0.05 & 0.05 & 0.05 & 0.05 & 0.15 & 0.15 & 0.15 & 0.15 \\
\hline
\end{tabular}




\subsubsection{Solving the Optimization Problem}

The performance metrics of the MODISLAI/FPAR operational algorithm includes (1) the retrieval index (RI), (2) RMSE between a reference LAI and LAI retrieved by the main algorithm, and (3) proximity of LAI histograms obtained from the main algorithm retrievals and reference data. The retrieval index is the percentage of pixels for which the main algorithm produces a retrieval. This index characterizes the spatial coverage of the best quality, high-precision retrievals and not their accuracies. The RMSE and proximity between the main algorithm retrievals and reference data characterize the product accuracy.

The validated MODIS C6 LAI product over selected regions (Section 2.3) with good-quality pixel BRFs (Section 3.1) generated by the main algorithm during the compositing period between 4 and 11 July 2002 is used as the reference dataset. The performance metrics are a function of the single scattering albedo at red and NIR spectral bands. The calibration procedure, therefore, can be formulated as follows: find a combination of single scattering albedos at red, $\omega_{\text {red }}$, and NIR, $\omega_{\text {NIR }}$, spectral bands which (a) maximizes the RI; (b) minimizes the RMSE; and (c) minimizes disagreement between LAI histograms generated by the main algorithm retrievals and the MODIS C6 LAI product. This procedure is illustrated in Figure 1. First, we calculated the RI and RMSE as a function of $\omega_{\text {red }}$ and $\omega_{\text {NIR }}$. Second, we separated a subset of pairs $\left(\omega_{\text {red }}, \omega_{\text {NIR }}\right)$ for which the RI exceeds pre-set values, which were set to $95 \%$ for herbaceous biomes (B1-B4), $80 \%$ for broadleaf biomes (B5 and B6), and 90\% for needleleaf biomes (B7 and B8). Finally, we selected a pair $\left(\omega_{\text {red }}, \omega_{\text {NIR }}\right)$ from this subset for which disagreement between LAI histograms obtained from the main algorithm retrievals and MODIS C6 LAI was minimized. Table 6 shows values of single scattering albedo at red and NIR spectral bands used in the MODIS C6 operational algorithm and adjusted for MAIAC data. These values optimally approximate the observed and true surface spectral BRF.

Table 6. Single scattering albedo at red and NIR spectral bands used in the MOSIS C6 operational algorithm and adjusted for the MAIAC data.

\begin{tabular}{ccccccccccc}
\hline & & Biome 1 & Biome 2 & Biome 3 & Biome 4 & Biome 5 & Biome 6 & Biome 7 & Biome 8 \\
\hline \multirow{2}{*}{ MAIAC } & $\omega_{\text {red }}$ & 0.21 & 0.16 & 0.15 & 0.16 & 0.15 & 0.15 & 0.15 & 0.15 \\
& $\omega_{\text {NIR }}$ & 0.88 & 0.83 & 0.94 & 0.88 & 0.92 & 0.84 & 0.70 & 0.70 \\
\hline \multirow{2}{*}{ MODIS } & $\omega_{\text {red }}$ & 0.18 & 0.16 & 0.1 & 0.14 & 0.151 & 0.14 & 0.14 & 0.14 \\
& $\omega_{\text {NIR }}$ & 0.88 & 0.84 & 0.94 & 0.88 & 0.91 & 0.84 & 0.7 & 0.7 \\
\hline \multirow{2}{*}{ MAIAC-MODIS } & $\Delta \omega_{\text {red }}$ & +0.030 & 0.000 & +0.050 & +0.020 & -0.001 & +0.010 & +0.010 & +0.010 \\
& $\Delta \omega_{\text {NIR }}$ & 0.000 & -0.010 & 0.000 & 0.000 & +0.010 & 0.000 & 0.000 & 0.000 \\
\hline
\end{tabular}

Figure 2a shows an example of model-based LUT entries used in the MODIS C6 operational algorithm and adjusted for the MAIAC data. For a given LAI and soil pattern the MAIAC LUT generates slightly higher BRF values at red spectral bands compared to that for MOD09GA data. The main algorithm accumulates acceptable solutions, i.e., all canopy/soil parameters for which observed spectral BRF, $\mathbf{r}$, agree with LUT entries, $\mathbf{r}_{M}$, within the stabilized precisions, i.e., $\chi_{\delta}^{2}\left[\mathbf{r}-\mathbf{r}_{M}\right] \leq 2$. Figure $2 \mathrm{~b}$ shows the distribution of LAI per unit in the NIR vs the red spectral plane. The retrieval domain is a set of points on the spectral plane for which the model-based main algorithm retrieves at least one acceptable solution. In the case of dense canopies, the reflectances saturate and, therefore, are weakly sensitive to changes in canopy properties. The saturated reflectances are shown as a yellow-to-red subset in the retrieval domain. The configuration of the retrieval domain is controlled by the stabilized precision and single scattering albedos at the red and NIR spectral bands.

Figure 3 shows comparisons of MODIS C6 and MAIAC LAI over selected regions with good-quality input for grasses and cereal crops (Biome 1), broadleaf crops (Biome 3), deciduous broadleaf forests (Biome 6), and deciduous needleleaf forests (Biome 7) generated by the main algorithm during the compositing period between 7 and 11 July 2002. The majority of the MAIAC LAI are close to the 1:1 line on the MAIAC vs. C6 LAI scatterplot. The upper bound of the difference 
between MAIAC and C6 LAIs has been reduced from 0.2 units to 0.05 LAI units after calibration of the LAI algorithm for MAIAC data (Table 4, rows 4-5), with the relative difference below $2 \%$. A comparison of the corresponding FPARs is shown in Figure S1, which is consistent with the LAI product.

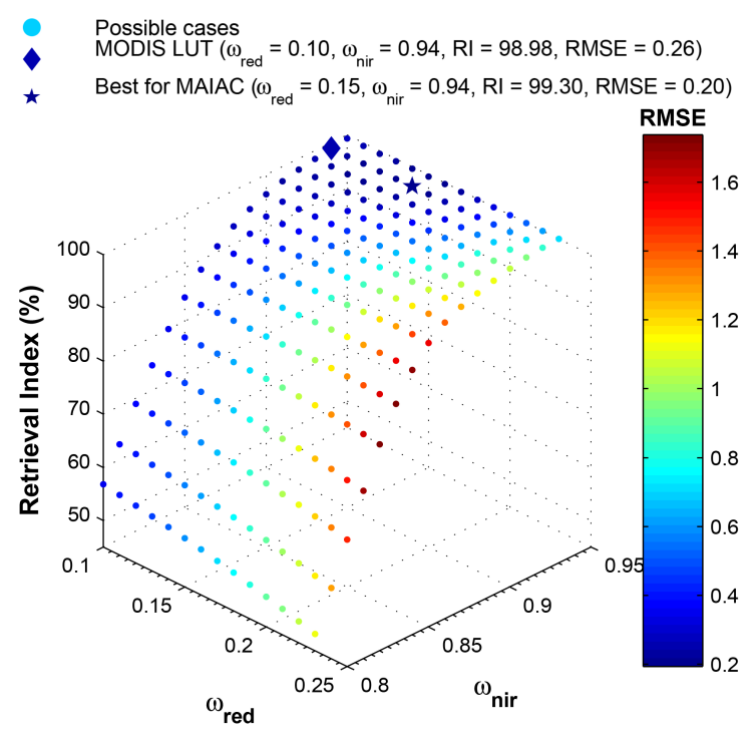

Figure 1. Retrieval index (vertical axis) and RMSE (color bar) as a function of single scattering albedo at red, $\omega_{\text {red }}$, and NIR, $\omega_{\text {NIR }}$, spectral bands (horizontal plane) for broadleaf crops (Biome 3 ). One can see a subset of pairs $\left(\omega_{\text {red }}, \omega_{\text {NIR }}\right)$ at which high values of the RI and low values of RMSE remain almost invariant. The LAI histograms, however, exhibit strong variation for these single scattering albedos. The calibration procedure aims to find a pair $\left(\omega_{\text {red }}, \omega_{\mathrm{NIR}}\right)$ from this subset that minimizes the disagreement between LAI histograms generated by the main algorithm retrievals and the MODIS C6 LAI product. The solution for the MAIAC BRF is shown as a star, which corresponds to $\omega_{\text {red }}=0.15, \omega_{\text {NIR }}=0.94, \mathrm{RI}=99.3$, and RMSE $=0.20$. The diamond shows single scattering albedos used in the MODIS C6 operational algorithm: $\omega_{\text {red }}=0.10, \omega_{\mathrm{NIR}}=0.94$.
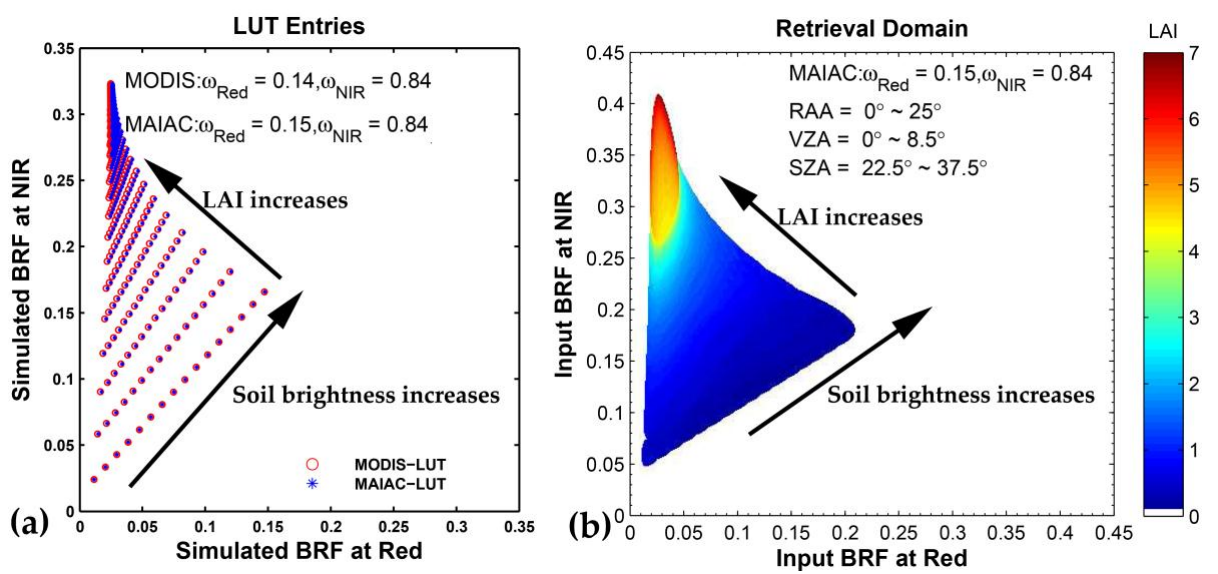

Figure 2. (a) Look-up-table (LUT) entries on the near-infrared (NIR) vs. red spectral plane adjusted for MOD09GA (circles) and MAIAC (asterisk) BRF data. (b) The retrieval domain of the algorithm calibrated for MAIAC BRF data. The main LAI algorithm can retrieve a LAI value only if the observed pair $\left(\mathrm{BRF}_{\text {red }}, \mathrm{BRF}_{\mathrm{NIR}}\right)$ of MAIAC BRF at red and NIR spectral bands falls within the retrieval domain. Color bars show the returned LAI values per unit red vs. NIR spectral planes. The LUT entries and retrieval domain are for broadleaf forests (Biome 6), a solar zenith angle between $22.5^{\circ}$ to $37.5^{\circ}$, a view zenith angle between $0^{\circ}$ to $8.5^{\circ}$, and the relative azimuth angle between $0^{\circ}$ to $25^{\circ}$. 


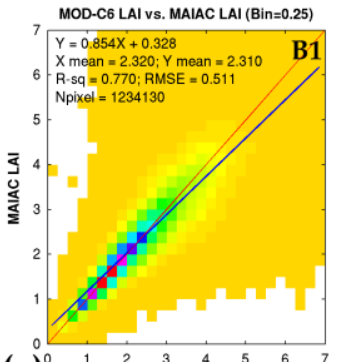

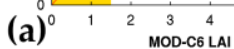
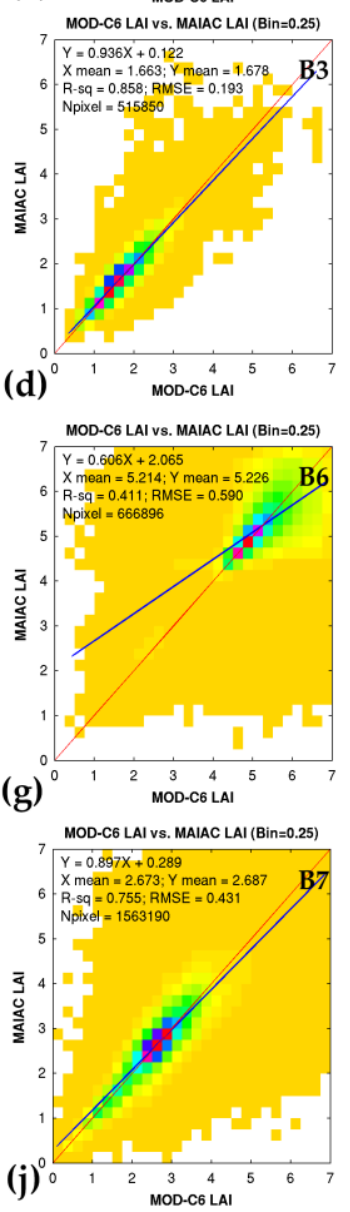

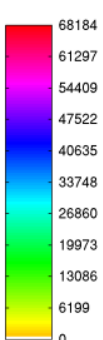

(b)
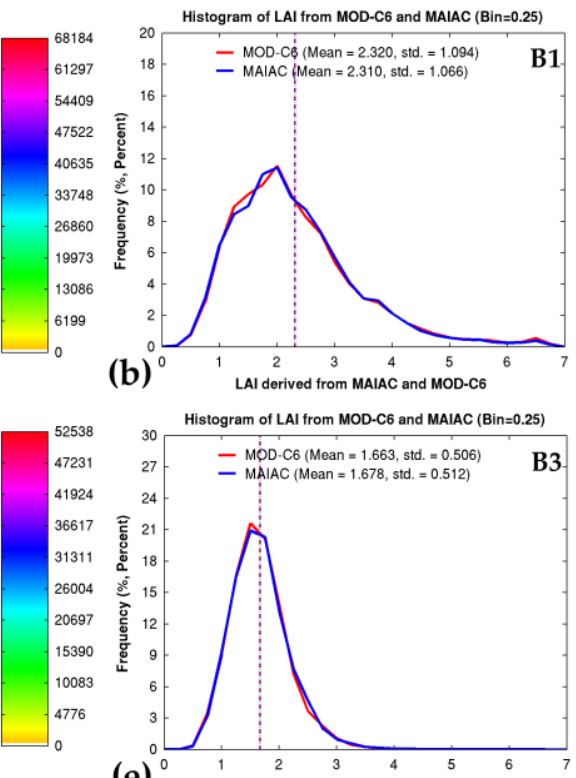

(e)
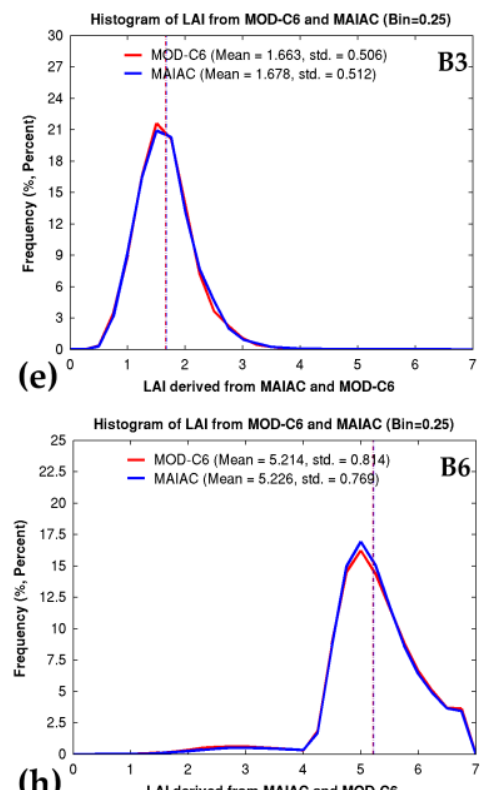

(h)
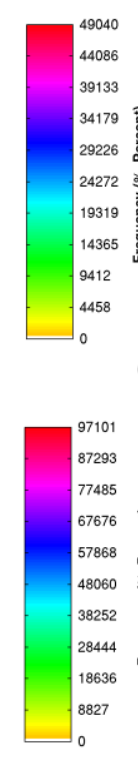

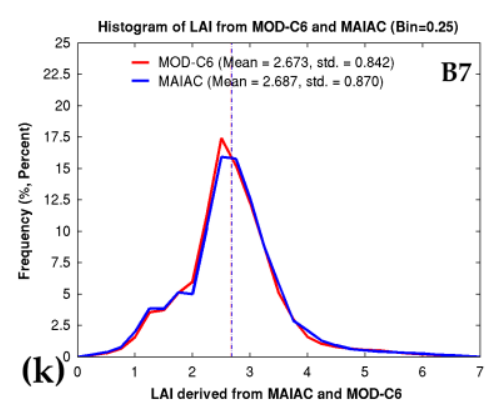

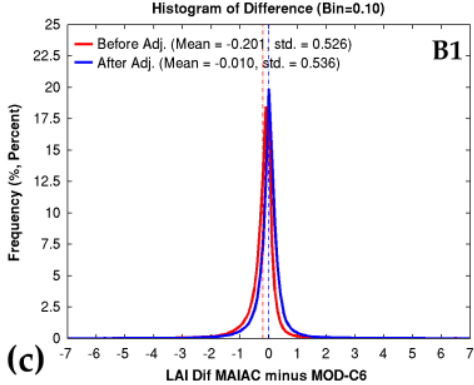

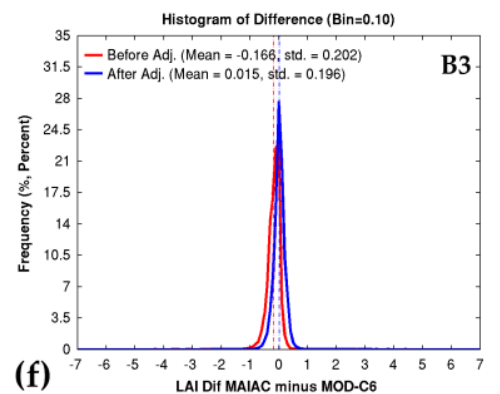

(f)
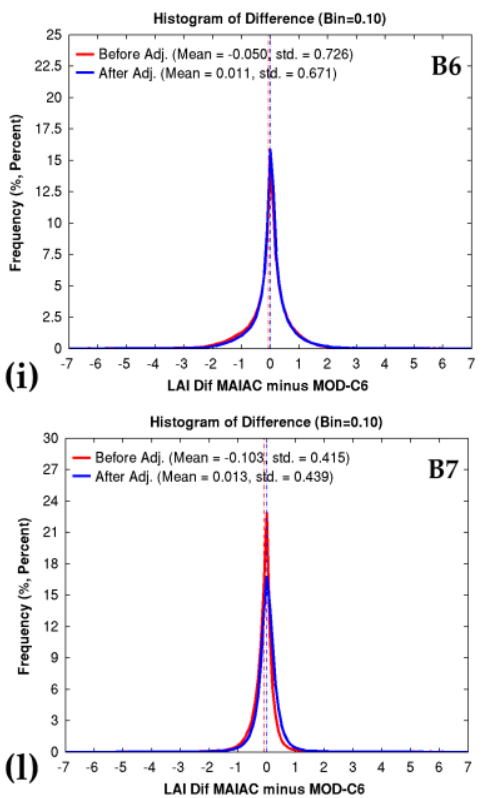

Figure 3. Comparison of MODIS C6 and MAIAC LAI over selected regions with good quality input for grasses and cereal crops (Biome 1, (a-c)), broadleaf crops (Biome 3, (d-f)), deciduous broadleaf forests (Biome 6, (g-i)), and deciduous needleleaf forests (Biome 7, (j-1)) generated by the main algorithm during the compositing period between 4 and 11 July 2002. Shown are MAIAC versus C6 LAIs scatterplots (first column), histograms of MAIAC (blue) and C6 (red) LAIs (second column), and the difference between retrievals before (red) and after (blue) calibration of the algorithm for MAIAC data (third column). The dashed vertical lines show mean values of the histograms.

\section{Results and Discussion}

We generated LAI and FPAR 8-day composites over the selected regions for 2002 from the MAIAC BRF using the calibrated MODIS LAI/FPAR operational algorithm. The aim of this section is to compare this dataset with the C6 LAI product. 


\subsection{MAIAC and C6 LAI for 2002}

Our analyses of MAIAC and C6 LAI were performed separately for subsets of good- and poor-quality pixels based on the 8-day composites. Table 7 summarizes the differences between the products for April through June, July through September, and the entirety of 2002. We also calculated annual maximum LAI as a biome-dependent spatial average of maximum pixel LAIs over the entirety of 2002. Its precision characterizes the stability of retrievals during the peak growing season when vegetated surface remains stable.

The MAIAC LAI product compares well with its C6 counterpart for the subset of good-quality pixels in the selected regions: the difference and precision between products are below 0.135 and 0.66 LAI units, respectively (Table 7). Their values are smaller in April through June compared to those in July through September. The annual difference (precision) depends on the biome type and varies between 0.003 (0.119) and 0.063 (0.503). The annual maximum LAI for the year of 2002 ranges from 0.004 to 0.139 , with precisions between 0.123 and 0.717 LAI units (Table 7).

For the subset of poor-quality pixels, the difference and precision exhibit a wider range of variation (Table 7). For most of the biomes and time periods, their values over poor-quality pixels are larger than those over good-quality pixels. The difference and precision reach maxima for annual maximum LAI, indicating a spurious variation in LAIs during peak growing seasons when vegetated surfaces remain stable.

Thus, the LAIs retrieved from MAIAC and MOD09GA BRF agree well over good-quality pixels. As it was shown in Section 3.1, the MAIAC retrieval technique is capable of producing reliable BRFs over pixels for which the MOD09GA algorithm detects cloud contamination and/or high aerosol content and, therefore, cannot generate high-quality BRFs. This lowers the quality of the LAI retrieved from MOD09GA in this case. The use of MAIAC BRF, therefore, increases spatial coverage of the best quality, high-precision LAI retrievals. For example, the use of MAIAC BRF in the LAI/FPAR algorithm provides up to $10 \%$ more reliable retrievals for the regions examined (Table 2).

Table 7. Difference between MAIAC and C6 LAI and precision for the year 2002.

\begin{tabular}{|c|c|c|c|c|c|c|c|c|c|}
\hline & \multirow{2}{*}{$\begin{array}{l}\text { Biome } \\
\text { Type }\end{array}$} & \multicolumn{2}{|c|}{ April-June } & \multicolumn{2}{|c|}{ July-September } & \multicolumn{2}{|c|}{ Year 2002} & \multicolumn{2}{|c|}{ Max LAI } \\
\hline & & $\bar{\delta}^{1}$ & $\sigma^{2}$ & $\bar{\delta}$ & $\sigma$ & $\bar{\delta}$ & $\sigma$ & $\bar{\delta}$ & $\sigma$ \\
\hline \multirow{10}{*}{$\begin{array}{l}\text { Good } \\
\text { quality } \\
\text { input }\end{array}$} & B1 & -0.011 & 0.251 & 0.041 & 0.464 & 0.026 & 0.344 & -0.035 & 0.717 \\
\hline & B2 & -0.011 & 0.115 & 0.007 & 0.126 & 0.006 & 0.119 & -0.017 & 0.123 \\
\hline & B3 & 0.005 & 0.129 & 0.135 & 0.303 & 0.063 & 0.206 & 0.139 & 0.41 \\
\hline & B4 & -0.038 & 0.216 & -0.018 & 0.151 & -0.029 & 0.236 & -0.112 & 0.405 \\
\hline & B5 & -0.044 & 0.385 & -0.004 & 0.303 & -0.02 & 0.336 & -0.058 & 0.25 \\
\hline & B6 & 0.018 & 0.413 & 0.01 & 0.66 & 0.025 & 0.503 & -0.021 & 0.59 \\
\hline & B7 & -0.034 & 0.247 & 0.013 & 0.421 & 0.003 & 0.354 & -0.025 & 0.472 \\
\hline & B8 & -0.001 & 0.235 & 0.05 & 0.428 & 0.039 & 0.353 & 0.004 & 0.485 \\
\hline & $\operatorname{Max} \mid * 1$ & 0.044 & 0.413 & 0.135 & 0.66 & 0.063 & 0.503 & 0.139 & 0.717 \\
\hline & $\operatorname{Min} \mid * 1$ & 0.001 & 0.115 & 0.004 & 0.126 & 0.003 & 0.119 & 0.004 & 0.123 \\
\hline \multirow{10}{*}{$\begin{array}{l}\text { Poor } \\
\text { quality } \\
\text { Input }\end{array}$} & B1 & -0.005 & 0.389 & 0.064 & 0.684 & 0.010 & 0.364 & 0.363 & 0.604 \\
\hline & B2 & -0.055 & 0.149 & -0.025 & 0.286 & -0.034 & 0.214 & 0.141 & 0.176 \\
\hline & B3 & -0.024 & 0.197 & 0.171 & 0.540 & 0.039 & 0.302 & 0.405 & 0.505 \\
\hline & B4 & -0.088 & 0.364 & -0.042 & 0.238 & -0.075 & 0.407 & 0.220 & 0.387 \\
\hline & B5 & 0.167 & 1.177 & 0.061 & 0.634 & 0.078 & 0.776 & 0.639 & 1.085 \\
\hline & B6 & 0.015 & 0.749 & 0.146 & 1.096 & 0.045 & 0.719 & 0.713 & 1.013 \\
\hline & B7 & -0.086 & 0.377 & 0.074 & 0.697 & 0.009 & 0.504 & 0.384 & 0.592 \\
\hline & B8 & -0.083 & 0.356 & 0.100 & 0.676 & 0.027 & 0.529 & 0.347 & 0.579 \\
\hline & $\operatorname{Max} \mid * 1$ & 0.167 & 1.177 & 0.171 & 1.096 & 0.078 & 0.776 & 0.713 & 1.085 \\
\hline & $\operatorname{Min} 1 * 1$ & 0.005 & 0.149 & 0.025 & 0.238 & 0.009 & 0.214 & 0.141 & 0.176 \\
\hline
\end{tabular}

$\overline{1} \bar{\delta}$ is the mean value of the LAI difference (accuracy), which is defined as MAIAC LAI - MODIS LAI. ${ }^{2} \sigma$ is the standard deviation of the LAI difference (precision). 


\subsection{Comparison with Field Data}

We compared the MAIAC and MODIS C6 LAI with the field data. The ground truth data used in our analyses are from the publicly available CalValPortal OLIVE archive (Section 2.5 and Table S1), which provides site-specific LAIs as spatially-averaged values over $3 \mathrm{~km} \times 3 \mathrm{~km}$ reference maps. Some data represent effective values of LAI, i.e., LAI measured by optical instruments, e.g., LAI-2000 Plant Canopy Analyzer, not all of them were corrected for clumping effects. The effective LAI may significantly underestimate true values in coniferous forests $[39,40]$. We use effective LAI of non-coniferous forest in our analyses.

We follow the technique developed for validation of the MODIS C6 LAI product with CalValPortal OLIVE data [3], which can be summarized as follows: Each site contains about $36(\sim 6 \times 6)$ MODIS C6 and MAIAC LAI pixels. First, we extracted 8-day composites, which include the date of the ground measurements and excludes water pixels. Second, we selected validation sites that contained more than $50 \%$ main algorithm retrievals within a $3 \mathrm{~km} \times 3 \mathrm{~km}$ site area and the information entropy of the site biome type was below 1 . The entropy is an indicator of the impact of biome mixture within a $3 \mathrm{~km} \times 3 \mathrm{~km}$ site area on LAI retrieval. Its values for our validation sites, documented in [3], were used in our analyses. There were 25 sites satisfying these conditions (Table 1). Finally, we compared the mean values of satellite-derived LAI over a $3 \mathrm{~km} \times 3 \mathrm{~km}$ area with their ground-measured counterparts.

Figure 4 summarizes the comparison results. The MAIAC LAI shows better agreement with field data than C6 with the RMSE decreasing from 0.80 LAI units (C6) down to 0.67 (MAIAC) and the $\mathrm{R}^{2}$ increasing from 0.69 to 0.80 . The slope (intercept) has changed from 0.89 (0.39) to 0.97 (0.25). Due to insufficient concurrent MAIAC and in situ FPAR data, assessment of the MAIAC FPAR is restricted to the comparisons with validated C6 FPAR with the goal to establish consistency between the products.

A better performance of the LAI algorithm with MAIAC BRF can be explained by a better stability of the MAIAC data. Indeed, in our analyses we used only those pixels for which both MAIAC and MOD09GA BRFs were available. This set includes pixels with good and poor quality data. The latter group consists mainly of pixels for which the MAIAC QA flag passed the "good quality" test, whereas MOD09GA QA indicated cloud contamination and/or high aerosol content. As it was shown in Section 3.1, the MAIAC BRF is more accurate and stable in this set, hence, a better overall performance of the LAI/FPAR algorithm.
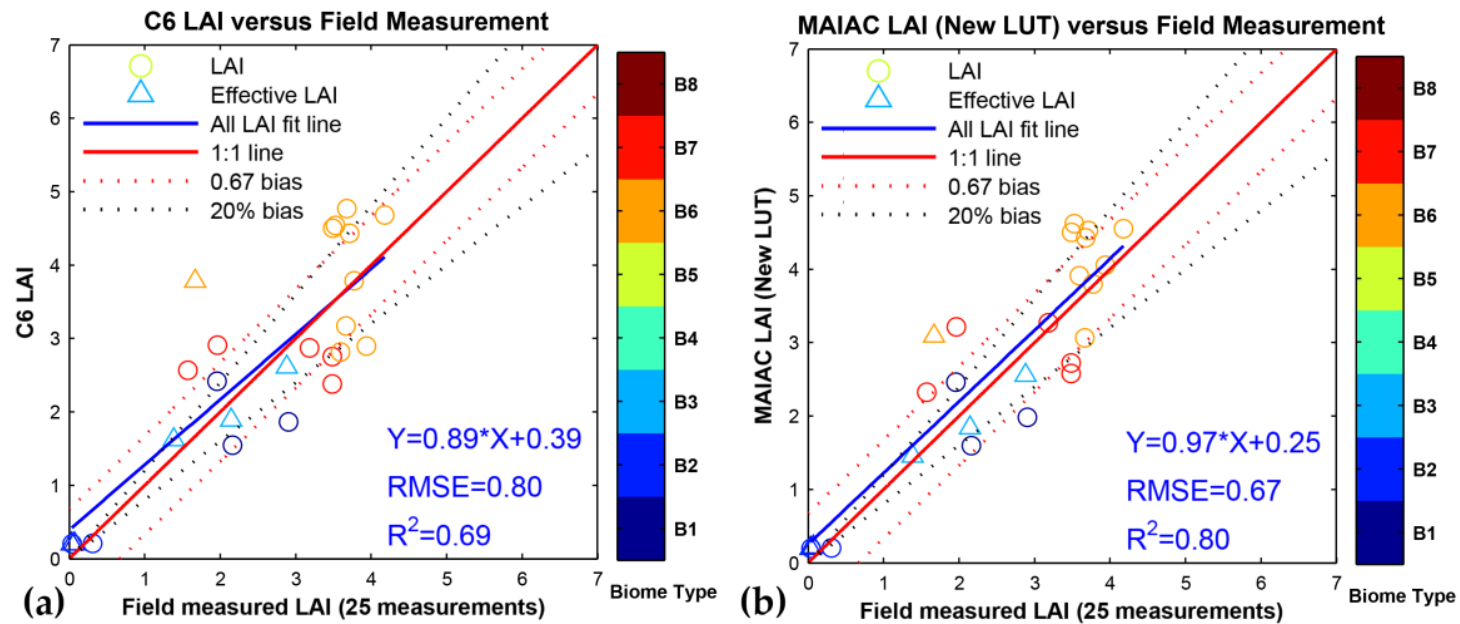

Figure 4. Comparisons of (a) C6 and (b) MAIAC with ground measured LAI. Effective and true LAI are shown as triangles and circles, respectively. There were 25 field measurements available for our analysis. 


\subsection{Seasonal LAI and FPAR Patterns Derived from MAIAC BRF}

Figure 5 and Figure S2 show the seasonal patterns of C6 and MAIAC LAI/FPAR 8-day composite over selected regions in 2002. Each LAI and FPAR time-series represent averaged biome-specific main algorithm retrievals. At the MODIS tile scale, the seasonal variations in the C6 and MAIAC LAI and FPAR products agree well. The regression line of the C6 vs. MAIAC LAI (FPAR) scatterplot has a slope of 0.998 (1.020) and an intercept of $-0.0005(-0.014)$. The $R^{2}$ coefficient is $0.999(0.997)$. The seasonal trajectories generally replicate typical shapes and magnitudes reported in the literature $[2,16,23,41]$. For MAIAC, maxima of non-forest LAI (Biomes 1 through 4) are typically below 2 (Figure S2). The LAI of North America's deciduous broadleaf (needleleaf) forests reach its maximum around 5 (3) during the boreal summer and drops to about $0.5(0.5)$ in winter. South America's tropic evergreen broadleaf forests (Biome 5) show weak seasonal LAI variations about its mean value of 5.5 LAI units. Savannas exhibit similar behavior with a mean LAI of 1.5 (Figure S2). The FPAR follows the seasonal patterns of LAI, as expected.
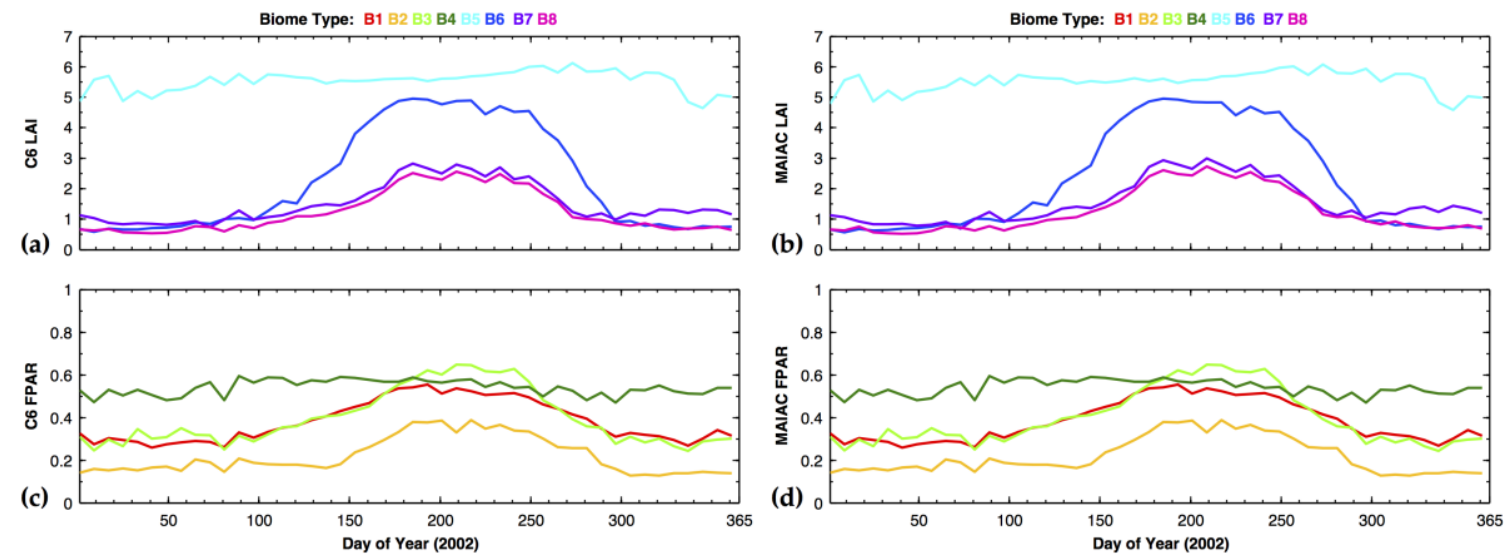

Figure 5. Seasonal variations in (a) C6 LAI and (b) MAIAC LAI of forests (B5-B8); (c) C6 FPAR and (d) MAIAC FPAR of non-forest (B1-B4) biome types in the year 2002. Retrievals generated by the main algorithm over selected regions were used to derive LAI and FPAR trajectories. LAI of non-forest and FPAR of forest biome types are shown in Figure S2.

\subsection{Algorithm Retrieval Index}

Figure 6 shows the distribution of the LAI/FPAR algorithm path's QA flag (Section 2.1) for MOD09GA and MAIAC input BRFs over good quality pixels in the selected regions for the year 2002. The RI exceeds $94 \%$ in both cases, not surprisingly, because the same procedure was applied to calibrate the LAI algorithm for MOD09GA and MAIAC BRF, which aims to maximize the RI. Figure 6a shows the RI as a function of biome type. The probability to retrieve the highest quality LAI (QA = "main algorithm without saturation") is higher than $94 \%$ for all biomes except broadleaf forests (Biome 5 and 6). Broadleaf forests represent dense canopies. The majority of LAIs are retrieved under the condition of saturation and, therefore, have moderate quality (QA = "main algorithm with saturation"). This is clearly seen in the case of South America's tropic evergreen broadleaf forests (Biome 5), which show weak seasonal LAI variations (Figure 4). The LAI of North America's deciduous broadleaf forests (Biome 6) exhibit strong seasonality (Figure 4). This lowers the frequency of LAIs retrieved under saturation conditions. Figure $6 \mathrm{~b}$ shows the seasonal variation of RI for all eight biomes in 2002. The main algorithm outputs the best quality retrievals, in the case of low LAI, and moderate quality, when LAI is high, as expected. 

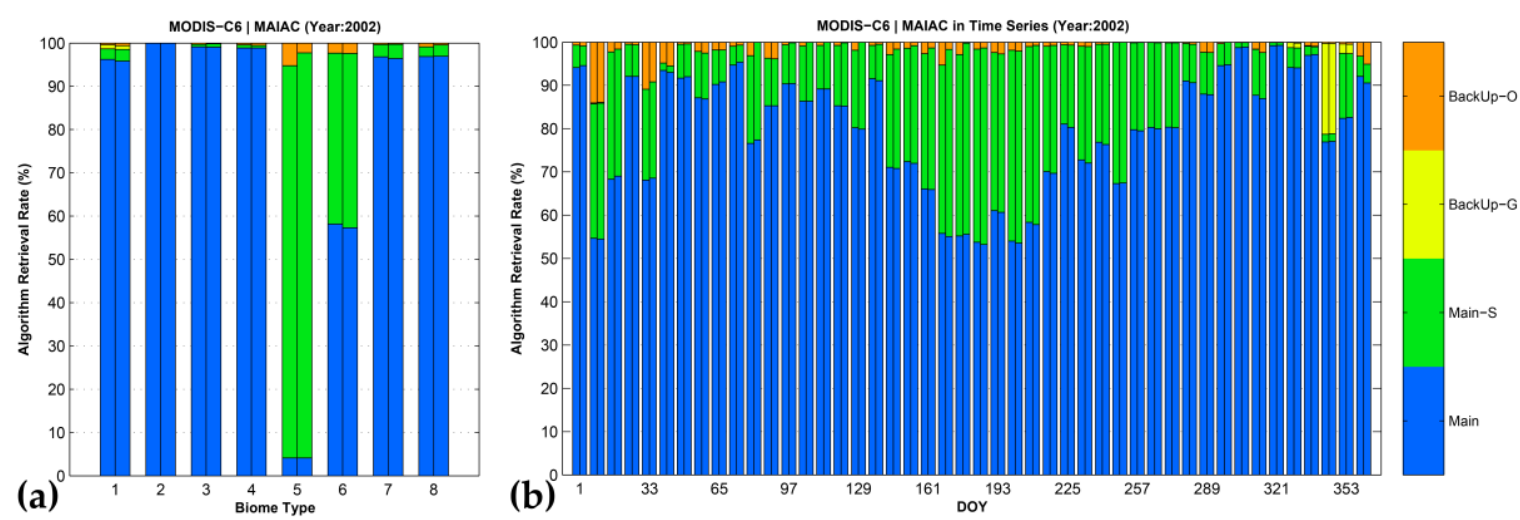

Figure 6. Distribution of the algorithm path QA flag over pixels with good quality pixels for MOD09GA (left bars) and MAIAC (right bars) input BRFs in the year 2002. The QA flag indicates whether LAI was generated by the main or backup algorithm. In the first case, a LAI value can be retrieved from non-saturated (legend "Main") or saturated (legend "Main-S") surface BRF. The backup algorithm is utilized if the main algorithm fails due to the sun-sensor geometry (legend "BackUp-G") or other reasons (legend “BackUp-O). (a) Distribution of QA flags for different biome types. (b) Seasonal variation of QA for all eight biome types.

\section{Conclusions}

The purpose of our study has been to evaluate the performance of the operational LAI/FPAR algorithm with MAIAC BRF data. Both the standard MOD09GA and MAIAC BRFs are derived from data acquired by the same instrument. However, different techniques were implemented to correct in-orbit data for atmosphere and other environmental effects. If MAIAC and standard BRF products were of the same quality, LAIs derived from the MAIAC BRF should compare well with the standard MODIS LAI product. Direct application of the LAI/FPAR operational algorithm to MAIAC data, however, resulted in an underestimation of the C6 LAI product. Both MAIAC and C6 LAIs are likely to agree well with ground truth data. However, their uncertainties are different. Model and observation uncertainties are input into the LAI/FPAR operational algorithm. Therefore, the use of incorrect uncertainty information when processing the MAIAC BRF data led to the deviation of the retrievals from the standard LAI product. The operational LAI/FPAR algorithm was calibrated for uncertainties in the MAIAC BRF product. Its performance was evaluated on a limited set of MAIAC BRF data from North and South America, and suggests increased spatial coverage of best quality, high-precision LAI retrievals of up to $10 \%$. The MAIAC LAI and FPAR show consistent values with their C 6 counterparts, and properly capture the seasonality in different biomes. The MAIAC LAI shows better agreement with the field data compared to the C6 LAI product with an RMSE decreasing from 0.80 LAI units (C6) down to 0.69 (MAIAC) and the $\mathrm{R}^{2}$ increasing from 0.67 to 0.80 . The slope (intercept) of the satellite-derived versus field measured LAI regression line has changed from $0.89(0.69)$ to $0.97(0.25)$. This is the consequence of a better quality of the MAIAC BRF, which is the input for the LAI/FPAR retrieval technique. Further evaluation of the LAI/FPAR retrievals with an emphasis on FPAR will be conducted when the MAIAC BRF is globally available for the entire MODIS period.

Supplementary Materials: The following are available online at www.mdpi.com/2072-4292/9/4/417/s1, Figure S1: Comparison of MODIS C6 and MAIAC FPAR over selected regions with good quality input. Figure S2: Supplementary seasonal patterns of MAIAC LAI/FPAR averaged over experimental tiles. Table S1: Validation sites and mean LAIs over $3 \mathrm{~km} \times 3 \mathrm{~km}$ areas. Table S2: Comparison of MOD09GA and MAIAC daily NIR BRF.

Acknowledgments: This work was funded by NASA Earth Science Division to MODIS (NNX14AI71G) and VIIRS (NNX14AP80A) programs through grants to Boston University (Ranga B. Myneni, PI), and HBO contract \#21205-14-036 to Yuri Knyazikhin.

Author Contributions: Chi Chen, Yuri Knyazikhin, Taejin Park and Ranga B. Myneni conceived and designed the experiments; Chi Chen and Taejin Park performed the experiments; Chi Chen, Yuri Knyazikhin, Taejin Park, 
Kai Yan and Bin Yang analyzed the data; Alexei Lyapustin and Yujie Wang contributed materials; and all authors wrote the paper.

Conflicts of Interest: The authors declare no conflict of interest.

\section{References}

1. Justice, C.O.; Townshend, J.; Vermote, E.F. An overview of MODIS land data processing and product status. Remote Sens. Environ. 2002, 83, 3-15. [CrossRef]

2. Yan, K.; Park, T.; Yan, G.; Chen, C.; Yang, B.; Liu, Z.; Nemani, R.; Knyazikhin, Y.; Myneni, R. Evaluation of MODIS LAI/FPAR Product Collection 6. Part 1: Consistency and improvements. Remote Sens. 2016, 8, 359. [CrossRef]

3. Yan, K.; Park, T.; Yan, G.; Liu, Z.; Yang, B.; Chen, C.; Nemani, R.; Knyazikhin, Y.; Myneni, R. Evaluation of MODIS LAI/FPAR Product Collection 6. Part 2: Validation and intercomparison. Remote Sens. 2016, 8, 460. [CrossRef]

4. Myneni, R.B.; Knyazikhin, Y.; Park, T. MOD15A2H MODIS/Terra Leaf Area Index/FPAR 8-Day L4 Global 500 m SIN Grid V006. NASA EOSDIS Land Processes DAAC. Available online: https:/ /pdaac.usgs.gov / dataset_discovery/modis/modis_products_table/mod15a2h_v006 (accessed on 16 October 2016).

5. Myneni, R.B.; Knyazikhin, Y.; Park, T. MYD15A2H MODIS/Aqua Leaf Area Index/FPAR 8-Day L4 Global 500 m SIN Grid V006. NASA EOSDIS Land Processes DAAC. Available online: https:/ /pdaac.usgs.gov / dataset_discovery/modis/modis_products_table/myd15a2h_v006 (accessed on 16 October 2016).

6. Myneni, R.B.; Knyazikhin, Y.; Park, T. MCD15A2H MODIS/Terra+Aqua Leaf Area Index/FPAR 8-Day L4 Global 500 m SIN Grid V006. NASA EOSDIS Land Processes DAAC. Available online: https:/ /pdaac.usgs. gov/dataset_discovery/modis/modis_products_table/mcd15a2h_v006 (accessed on 16 October 2016).

7. Myneni, R.B.; Knyazikhin, Y.; Park, T. MCD15A3H MODIS/Terra+Aqua Leaf Area Index/FPAR 4-Day L4 Global 500 m SIN Grid V006. NASA EOSDIS Land Processes DAAC. Available online: https://lpdaac.usgs. gov/dataset_discovery/modis/modis_products_table/mcd15a3h_v006 (accessed on 16 October 2016).

8. Sellers, P.J.; Dickinson, R.E.; Randall, D.A.; Betts, A.K.; Hall, F.G.; Berry, J.A.; Collatz, G.J.; Denning, A.S.; Mooney, H.A.; Nobre, C.A.; et al. Modeling the exchanges of energy, water, and carbon between continents and the atmosphere. Science 1997, 275, 502-509. [CrossRef] [PubMed]

9. Lyapustin, A.; Martonchik, J.; Wang, Y.; Laszlo, I.; Korkin, S. Multiangle implementation of atmospheric correction (MAIAC): 1. Radiative transfer basis and look-up tables. J. Geophys. Res. Atmos. 2011, 116, D03210. [CrossRef]

10. Lyapustin, A.; Wang, Y.; Laszlo, I.; Kahn, R.; Korkin, S.; Remer, L.; Levy, R.; Reid, J.S. Multiangle implementation of atmospheric correction (MAIAC): 2. Aerosol algorithm. J. Geophys. Res. Atmos. 2011, 116, D03211. [CrossRef]

11. Lyapustin, A.I.; Wang, Y.; Laszlo, I.; Hilker, T.; Hall, F.G.; Sellers, P.J.; Tucker, C.J.; Korkin, S.V. Multi-angle implementation of atmospheric correction for MODIS (MAIAC): 3. Atmospheric correction. Remote Sens. Environ. 2012, 127, 385-393. [CrossRef]

12. Vermote, E.F.; Vermeulen, A. Atmospheric Correction Algorithm: Spectral Reflectances (MOD09). Available online: http://dratmos.geog.umd.edu/files/pdf/atbd_mod09.pdf (accessed on 14 April 2017).

13. Knyazikhin, Y.; Glassy, J.; Privette, J.L.; Tian, Y.; Lotsch, A. MODIS Leaf Area Index (LAI) and Fraction of Photosynthetically Active Radiation Absorbed by Vegetation (FPAR) Product (MOD15) Algorithm Theoretical Basis Document. Available online: https://www.researchgate.net/publication/236770186_ MODIS_Leaf_Area_Index_LAI_and_Fraction_of_Photosynthetically_Active_Radiation_Absorbed_by_ Vegetation_FPAR_Product_MOD15_Algorithm_Theoretical_Basis_Document (accessed on 14 April 2017).

14. Knyazikhin, Y.; Martonchik, J.V.; Myneni, R.B.; Diner, D.J.; Running, S.W. Synergistic algorithm for estimating vegetation canopy leaf area index and fraction of absorbed photosynthetically active radiation from MODIS and MISR data. J. Geophys. Res. Atmos. 1998, 103, 32257-32275. [CrossRef]

15. Myneni, R.B.; Hoffman, S.; Knyazikhin, Y.; Privette, J.L.; Glassy, J.; Tian, Y.; Wang, Y.; Song, X.; Zhang, Y.; Smith, G.R.; et al. Global products of vegetation leaf area and fraction absorbed PAR from year one of MODIS data. Remote Sens. Environ. 2002, 83, 214-231. [CrossRef] 
16. Yang, W.; Huang, D.; Tan, B.; Stroeve, J.C.; Shabanov, N.V.; Knyazikhin, Y.; Nemani, R.R.; Myneni, R.B. Analysis of leaf area index and fraction of PAR absorbed by vegetation products from the terra MODIS sensor: 2000-2005. IEEE Trans. Geosci. Remote Sens. 2006, 44, 1829-1842. [CrossRef]

17. Yang, W.; Tan, B.; Huang, D.; Rautiainen, M.; Shabanov, N.V.; Wang, Y.; Privette, J.L.; Huemmrich, K.F.; Fensholt, R.; Sandholt, I. MODIS leaf area index products: From validation to algorithm improvement. IEEE Trans. Geosci. Remote Sens. 2006, 44, 1885-1898. [CrossRef]

18. Vermote, E.; Wolfe, R. MOD09GA MODIS/Terra Surface Reflectance Daily L2G Global $1 \mathrm{~km}$ and $500 \mathrm{~m}$ SIN Grid V006. NASA EOSDIS Land Processes DAAC. Available online: https://lpdaac.usgs.gov/dataset_ discovery/modis/modis_products_table/mod09ga_v006 (accessed on 16 October 2016).

19. NASA-Goddard Space Flight Center. Sinusoidal Tile Grid. Available online: https://modis-land.gsfc.nasa. gov/MODLAND_grid.html (accessed on 16 October 2016).

20. Hilker, T.; Lyapustin, A.I.; Tucker, C.J.; Sellers, P.J.; Hall, F.G.; Wang, Y. Remote sensing of tropical ecosystems: Atmospheric correction and cloud masking matter. Remote Sens. Environ. 2012, 127, 370-384. [CrossRef]

21. Hilker, T.; Lyapustin, A.I.; Tucker, C.J.; Hall, F.G.; Myneni, R.B.; Wang, Y.; Bi, J.; de Moura, Y.M.; Sellers, P.J. Vegetation dynamics and rainfall sensitivity of the Amazon. Proc. Natl. Acad. Sci. USA 2014, 111, 16041-16046. [CrossRef] [PubMed]

22. Hilker, T.; Lyapustin, A.I.; Hall, F.G.; Myneni, R.; Knyazikhin, Y.; Wang, Y.; Tucker, C.J.; Sellers, P.J. On the measurability of change in Amazon vegetation from MODIS. Remote Sens. Environ. 2015, 166, $233-242$. [CrossRef]

23. Yang, W.; Shabanov, N.V.; Huang, D.; Wang, W.; Dickinson, R.E.; Nemani, R.R.; Knyazikhin, Y.; Myneni, R.B. Analysis of leaf area index products from combination of MODIS Terra and Aqua data. Remote Sens. Environ. 2006, 104, 297-312. [CrossRef]

24. European Space Agency. CEOS Calibration Validation Portal. Available online: http://calvalportal.ceos. org/web/olive/site-description (accessed on 16 October 2016).

25. Garrigues, S.; Lacaze, R.; Baret, F.; Morisette, J.T.; Weiss, M.; Nickeson, J.E.; Fernandes, R.; Plummer, S.; Shabanov, N.V.; Myneni, R.B.; et al. Validation and intercomparison of global Leaf Area Index products derived from remote sensing data. J. Geophys. Res. 2008, 113, G02028. [CrossRef]

26. Morisette, J.T.; Baret, F.; Privette, J.L.; Myneni, R.B.; Nickeson, J.E.; Garrigues, S.; Shabanov, N.V.; Weiss, M.; Fernandes, R.A.; Leblanc, S.G.; et al. Validation of global moderate-resolution LAI products: A framework proposed within the CEOS land product validation subgroup. IEEE Trans. Geosci. Remote Sens. 2006, 44, 1804-1817. [CrossRef]

27. Fan, L.; Berger, F.H.; Liu, H.; Bernhofer, C.; Fan, L.; Berger, F.H.; Liu, H.; Bernhofer, C. Validating MODIS land surface reflectance products using ground-measured reflectance spectra-A case study in semi-arid grassland in Inner Mongolia, China. Int. J. Remote Sens. 2014, 35, 1715-1728. [CrossRef]

28. Wang, Y.; Lyapustin, A.I.; Privette, J.L.; Cook, R.B.; SanthanaVannan, S.K.; Vermote, E.F.; Schaaf, C.L. Assessment of biases in MODIS surface reflectance due to Lambertian approximation. Remote Sens. Environ. 2010, 114, 2791-2801. [CrossRef]

29. Wang, Y.; Tian, Y.; Zhang, Y.; El-Saleous, N.; Knyazikhin, Y.; Vermote, E.; Myneni, R.B. Investigation of product accuracy as a function of input and model uncertainties. Remote Sens. Environ. 2001, 78, $299-313$. [CrossRef]

30. Tan, B.; Hu, J.; Zhang, P.; Huang, D.; Shabanov, N. Validation of Moderate Resolution Imaging Spectroradiometer leaf area index product in croplands of Alpilles, France. J. Geophys. Res. 2005, 110, D01107. [CrossRef]

31. Tan, B.; Hu, J.; Huang, D.; Yang, W.; Zhang, P.; Shabanov, N.V.; Knyazikhin, Y.; Nemani, R.R.; Myneni, R.B. Assessment of the broadleaf crops leaf area index product from the Terra MODIS instrument. Agric. For. Meteorol. 2005, 135, 124-134. [CrossRef]

32. Hu, J.; Tan, B.; Shabanov, N.; Crean, K.A.; Martonchik, J.V.; Diner, D.J.; Knyazikhin, Y.; Myneni, R.B. Performance of the MISR LAI and FPAR algorithm: A case study in Africa. Remote Sens. Environ. 2003, 88, 324-340. [CrossRef]

33. Bronshtein, I.N.; Semendyayev, K.A.; Musiol, G.; Mühlig, H. Handbook of Mathematics; Springer: Berlin/Heidelberg, Germany, 2015. 
34. Knyazikhin, Y.; Myneni, R.B.; Tian, Y.; Wang, Y.; Zhang, Y. Estimation of vegetation canopy leaf area index and fraction of photosynthetically active radiation absorbed by vegetation from remotely sensed multi-angle and multi-spectral data. In Proceedings of the IEEE 1999 International Geoscience and Remote Sensing Symposium, IGARSS'99 Proceedings, Hamburg, Germany, 28 June-2 July 1999; Volume 3, pp. 1872-1874.

35. Huang, D.; Knyazikhin, Y.; Dickinson, R.E.; Rautiainen, M.; Stenberg, P.; Disney, M.; Lewis, P.; Cescatti, A.; Tian, Y.; Verhoef, W.; et al. Canopy spectral invariants for remote sensing and model applications. Remote Sens. Environ. 2007, 106, 106-122. [CrossRef]

36. Knyazikhin, Y.; Schull, M.A.; Xu, L.; Myneni, R.B.; Samanta, A. Canopy spectral invariants. Part 1: A new concept in remote sensing of vegetation. J. Quant. Spectrosc. Radiat. Transf. 2011, 112, 727-735. [CrossRef]

37. Knyazikhin, Y.; Schull, M.A.; Stenberg, P.; Mõttus, M.; Rautiainen, M.; Yang, Y.; Marshak, A.; Carmona, P.L.; Kaufmann, R.K.; Lewis, P.; et al. Hyperspectral remote sensing of foliar nitrogen content. Proc. Natl. Acad. Sci. USA 2013, 110, E185-E192. [CrossRef] [PubMed]

38. Ganguly, S.; Schull, M.; Samanta, A.; Shabanov, N.; Milesi, C.; Nemani, R.; Knyazikhin, Y.; Myneni, R. Generating vegetation leaf area index earth system data record from multiple sensors. Part 1: Theory. Remote Sens. Environ. 2008, 112, 4333-4343. [CrossRef]

39. Rautiainen, M.; Mõttus, M.; Stenberg, P. On the relationship of canopy LAI and photon recollision probability in boreal forests. Remote Sens. Environ. 2009, 113, 458-461. [CrossRef]

40. Chen, J.M.; Cihlar, J. Quantifying the effect of canopy architecture on optical measurements of leaf area index using two gap size analysis methods. IEEE Trans. Geosci. Remote Sens. 1995, 33, 777-787. [CrossRef]

41. Tian, Y. Comparison of seasonal and spatial variations of leaf area index and fraction of absorbed photosynthetically active radiation from Moderate Resolution Imaging Spectroradiometer (MODIS) and Common Land Model. J. Geophys. Res. 2004, 109, D01103. [CrossRef]

(C) 2017 by the authors. Licensee MDPI, Basel, Switzerland. This article is an open access article distributed under the terms and conditions of the Creative Commons Attribution (CC BY) license (http:/ / creativecommons.org/licenses/by/4.0/). 